\title{
FRAILTY SYNDROME AND ANTHROPOMETRIC MEASUREMENTS IN THE ELDERLY LIVING AT HOME
}

\author{
R.A. Partezani Rodrigues ${ }^{1}$, J.R. Silva Fhon ${ }^{1}$, V.M. Rojas Huayta², W.L. Fuentes Neira ${ }^{3}$, \\ M. de Lourdes de Farias Pontes ${ }^{4}$, A.O. Silva ${ }^{4}$, G.P. Cardoso Defina ${ }^{1}$
}

\begin{abstract}
Disturbance in the nutritional status in the elderly can change anthropometric measurements. These changes on their body could associated with frailty syndrome. The aim was to assess the frailty syndrome and its association with demographic variables and anthropometric measures. Cross-sectional study with 235 elderly people living at home. Descriptive statistics applied were measures of central tendency and dispersion, with frequencies for the qualitative variables. Student's t test was used to compare the means of sex with age, weight, height, waist circumference, waist/height ratio, body mass index and frailty and multinomial logistic regression analysis between categories of frailty and demographic and anthropometric variables. It was significant $\mathrm{p} \leq 0.05$. There was a relationship between gender and body weight, waist circumference and the waist/height ratio; the data also showed that frailty increases with age. It was found that having a waist/height ratio $\geq 0.50$ and a body mass index $\geq 27$ increased the risk of frailty. The study shows that the association between frailty and anthropometric measures should be a priority in elderly care.
\end{abstract}

Key words: Aged, frail elderly, anthropometry, geriatric nursing, elderly nutrition.

\section{Introduction}

The world population is aging rapidly. In Brazil, this change has also been observed and according to the census conducted in 2010, 23.5 million people are aged 60 or older, and increased life expectancy in 2013 was 74.8 years with predictions for 2041 of 80 years old (1).

With the aging process, the person may suffer different syndromes, including frailty, which can lead to a state of vulnerability impacting the lives of the elderly, the family and their social environment.

The concept of frailty has been widely discussed among researchers in recent years and involves both cognitive and social aspects. However, the research considers the physical condition to be the most vulnerable in the elderly. In the consensus group on the subject, researchers understand frailty to be "a medical syndrome with multiple causes, characterized by decreased strength, endurance and reduced physiological function

1. Ribeirão Preto College of Nursing, University of São Paulo, Ribeirão Preto, São Paulo, Brazil; 2. Professional Academic School of Nutrition, National University of San Marcos, Lima, Peru; 3. Faculty of Health Sciences, University of Sciences and Humanities, Lima, Peru; 4. Department of Public Health Nursing and Psyquiatric, Federal University of Paraiba, João Pessoa, Brazil.

Corresponding Author: Rosalina Aparecida Partezani Rodrigues, Nursing School of Ribeirão Preto, University of São Paulo. 3900 dos Bandeirantes Avenue, Monte Alegre District, CEP 14040-902 Ribeirão Preto City, São Paulo State, Brazil. Tel.: +55 163315-3416 E-mail address: rosalina@eerp.usp.br with increasing individual vulnerability" (2).

However, along with nurses' care of elderly patients, multidimensional assessment is an important aspect to be considered. In evaluating the different concepts of frailty, that which most seems to fit the practice of the nurse is the proposed methodological framework of the Canadian Initiative on Frailty and Aging, which takes a holistic approach to frailty (biological, psychological and social) and draws on the history or the life history of the elderly subject (3), and considers aging to be a multidimensional construct.

The prevalence of frailty varies between $4 \%$ and $59.1 \%$ (4)), increases with age (4-7) and is more prevalent in females $(2,4)$.

The frailty syndrome is associated with weight loss, being overweight and obesity which increases the risk of functional limitations and disability in the individual (5). In the aging process, frailty can present related malnutrition leading to a loss of muscle mass and strength (6). Risks to the health of the elderly who are overweight include increased chronic diseases, limitations and functional incapacity leading to frailty (5).

With the aging process, relevant changes in body composition affect the nutritional status of the elderly, leading to observed changes in anthropometric measures such as weight and height due to a decrease in the intervertebral space and increased spinal curves in need 
of comprehensive assessment (7). It is also important to assess the body mass index (BMI) and the waist/height ratio (WHtR), these measures are useful, inexpensive and non-invasive (6).

It is important to maintain an adequate nutritional status in the elderly to prevent frailty syndrome. This topic is still under discussion in the literature of gerontology and geriatrics. Thus, this study is justified by the importance of the syndrome, since the use of WHtR is little used for research into frailty and deserves deeper attention. From this analysis, the results may contribute to a more detailed clinical assessment of the elderly in health services. The objective was to evaluate the frailty syndrome and its association with demographic variables (gender, age and marital status) and anthropometric measures of the elderly living at home.

\section{Method}

\section{Study design and participants}

This is a descriptive, quantitative and cross-sectional study conducted in the city of Ribeirão Preto, Sao Paulo, Brazil, with 240 elderly subjects. The recruitment of participants was performed in two steps. The first sampling unit considered was the electoral sectors: at the time of data collection, the city had 639 sectors and one district with 11 sectors, making a total of 650 sectors. The second step considered a person aged 60 or more. We selected 20 sectors at random and interviewed 12 elderly people per census sector, guaranteeing a maximum error of $6.3 \%$ with $95 \%$ probability.

Inclusion criteria were being aged 60 years, of both gender, living at home and being able to communicate verbally.

The Research Ethics Committee of the Ribeirão Preto School of Nursing, University of São Paulo approved the research project with CAAE process number 47155115.3.0000.539.

\section{Data collection and measurements}

Data collection was carried out between November 2011 and February 2012, by means of interviews in the subjects' homes lasting approximately 40 minutes and performed by trained investigators to obtain the information.

The following instruments were used:

a) Demographic profile: to obtain information on the variables of gender (male and female), age (in years) and marital status (with partner and without partner).

b) Edmonton Frail Scale (EFS): created by the Canadian Initiative on Frailty and Aging group (CIF-A) (8) and validated for Portuguese in Brazil $(9,10)$. The scale evaluates nine domains represented by 11 items: a) cognitive area by the test clock $(1)$; b) general health status (2); c) functional independence (1). d) social support (1); e) medication use (2); f) nutrition (1); g) mood (1); h) continence (1); i) functional performance with the timed get up and go test to evaluate balance and mobility (1). The scoring system runs from 0-17 points with categories of "not frail", "seemingly vulnerable" and "frail" (mild, moderate and severe) and will be used to define the frailty level of the subject.

c) Anthropometric measurements:

Each subject was weighed without shoes and wearing minimal clothing on the Camry model EB903 electronic digital scale with a maximum capacity of 150 kilograms.

Height was measured using a graduated scale in centimeters $(\mathrm{cm})$ and millimeters $(\mathrm{mm})$ with a maximum height of $200 \mathrm{~cm}$.

Abdominal Circumference (AC) was measured using a tape measure of $200 \mathrm{~cm}$ in length around the middle point between the iliac crest and the last rib; the measure for females is $\geq 80.0 \mathrm{~cm}$ and for males is $94.0 \mathrm{~cm}$ (11); an AC above these values for both genders means that the person is at risk of suffering cardiovascular diseases.

The Body Mass Index (BMI) was calculated by dividing the weight in kilograms by the square of the height in centimeters [weight $(\mathrm{kg})$ /height2 (m)]. For all subjects, a BMI of $\leq 22$ was considered underweight, 22.1 to 26.9 healthy and $\geq 27$ overweight (11).

Waist/height ratio (WHtR) was calculated using the $\mathrm{AC}$ and the height in centimeters (AC/height) with a cut-off point of 0.50 indicating higher risk of cardio-metabolic diseases such as diabetes mellitus, stroke, Systemic Arterial Hypertension (SAH) and dyslipidemia (12).

We analyzed the data in Microsoft Excel ${ }^{\circledR}$ applying double entry and internal consistency, and later transferred it to the Statistical Package for Social Sciences SPSS v. 22.0

During data analysis, it was observed that of the 240 participants in the sample, five lacked data for height and/or weight, and were therefore excluded from the final analysis of 235 elderly subjects.

The descriptive statistics used for the quantitative variables were a central tendency measure (mean) and dispersion (standard deviation) with frequencies for the qualitative variables.

For the different analyses, the dependent variable, being the frailty syndrome, was subdivided on the scale into the categories "not frail", "vulnerable" and "frail" (mild, moderate and severe) and the dichotomous independent variables such as gender and marital status were categorized as male/female and with/without a partner. For the anthropometric measurements, AC was divided into adequate ( $<80 \mathrm{~cm}$ in women and $<94$ in men) and inappropriate ( $\geq 80$ in women and $\geq 94$ men); WHtR was divided into $<0.50$ and $\geq 0.50$; for $\mathrm{BMI}, \leq 22$ was categorized as underweight, 22.1 to 26.9 healthy and $\geq 27$ 
Table 1

Distribution of means and frequencies of elderly living at home by sex, Ribeirão Preto, SP, Brazil, 2012

\begin{tabular}{|c|c|c|c|c|}
\hline Variables & $\begin{array}{c}\text { Male } \\
\text { n / Mean (=SD) }\end{array}$ & $\begin{array}{c}\text { Female } \\
\text { n / Mean (=SD) }\end{array}$ & $\begin{array}{c}\text { Total } \\
\text { n / Mean (=SD) }\end{array}$ & p-value \\
\hline Number & $90(38.3 \%)$ & $145(61.7 \%)$ & & \\
\hline \multicolumn{5}{|c|}{ Demographic profile } \\
\hline Age (years) & $74.51(7.79)$ & $72.03(8.27)$ & $72.98(8.16)$ & 0.023 \\
\hline \multicolumn{5}{|l|}{ Marital status } \\
\hline With partner & $72(51.8 \%)$ & $67(48.2 \%)$ & $139(59.1 \%)$ & \\
\hline Without partner & $18(18.8 \%)$ & $78(81.3 \%)$ & $96(40.9 \%)$ & \\
\hline \multicolumn{5}{|c|}{ Anthropometric variables } \\
\hline Weight (kg) & $73.94(14.27)$ & $65.23(13.51)$ & $68.56(14.41)$ & $<0.001$ \\
\hline $\mathrm{AC}(\mathrm{cm})$ & $100.78(11.82)$ & $95.43(13.39)$ & $97.47(13.05)$ & 0.002 \\
\hline BMI & $26.19(4.63)$ & $27.40(5.17)$ & $26.94(5.00)$ & 0.072 \\
\hline WHtR & $0.59(0.09)$ & $0.61(0.08)$ & $0.60(0.08)$ & 0.032 \\
\hline Frailty & $5.69(3.05)$ & $5.82(3.05)$ & $5.77(3.04)$ & 0.748 \\
\hline
\end{tabular}

Table 2

Association of the Edmonton Frail Scale categories with gender and anthropometric measures of the elderly living at home. Ribeirão Preto, SP, Brazil

\begin{tabular}{|c|c|c|c|c|c|}
\hline Variables & $\mathbf{n}$ & $\begin{array}{l}\text { Frail } \\
\text { n (\%) }\end{array}$ & $\begin{array}{c}\text { Vulnerable } \\
\text { n (\%) }\end{array}$ & $\begin{array}{c}\text { Not frail } \\
\text { n }(\%)\end{array}$ & p-value \\
\hline \multicolumn{6}{|c|}{ Socio-demographic profile } \\
\hline Age (mean, SD) & & $77.40(7.46)$ & $72.86(7.81)$ & $68.63(6.61)$ & $<0.001 \dagger$ \\
\hline \multicolumn{6}{|l|}{ Gender } \\
\hline Male & 90 & $32(35.6)$ & $25(27.8)$ & $33(36.7)$ & $0.604^{*}$ \\
\hline Female & 145 & $57(39.3)$ & $32(22.1)$ & $56(38.6)$ & \\
\hline \multicolumn{6}{|l|}{ Marital status } \\
\hline With partner & 139 & $48(34.5)$ & $35(25.2)$ & $56(40.3)$ & $0.439^{*}$ \\
\hline Without partner & 96 & $41(42.7)$ & $22(22.9)$ & $33(34.4)$ & \\
\hline \multicolumn{6}{|c|}{ Anthropometric variables } \\
\hline \multicolumn{6}{|l|}{$\mathrm{AC}$} \\
\hline Adequate & 46 & $21(45.7)$ & $10(21.7)$ & $15(32.6)$ & $0.477^{*}$ \\
\hline Inadequate & 189 & $68(36.0)$ & $47(24.9)$ & $74(39.2)$ & \\
\hline \multicolumn{6}{|l|}{ WHtR } \\
\hline$<0.50$ & 115 & $39(33.9)$ & $26(22.6)$ & $50(43.5)$ & $0.217^{*}$ \\
\hline$\geq 0.50$ & 120 & $50(41.7)$ & $31(25.8)$ & $39(32.5)$ & \\
\hline \multicolumn{6}{|l|}{ BMI } \\
\hline$\leq 22.0$ & 37 & $22(59.5)$ & $6(16.2)$ & $9(24.3)$ & $0.045^{*}$ \\
\hline $22.1-26.9$ & 87 & $26(29.9)$ & $24(27.6)$ & $37(42.5)$ & \\
\hline$\geq 27.0$ & 111 & $41(36.9)$ & $27(24.3)$ & $43(38.7)$ & \\
\hline
\end{tabular}


Table 3

Multinomial logistic regression model of the Edmonton Frail Scale categories adjusted for age, gender, marital status, and anthropometric measures. Ribeirão Preto, SP, 2012

\begin{tabular}{|c|c|c|c|c|c|c|}
\hline \multirow[b]{2}{*}{ Variables } & \multicolumn{3}{|c|}{ Frail } & \multicolumn{3}{|c|}{ Vulnerable } \\
\hline & B & OR $(95 \% \mathrm{CI})$ & p-value & B & OR $(95 \% \mathrm{CI})$ & p-value \\
\hline \multicolumn{7}{|l|}{ Demographic profile } \\
\hline Age & 0.163 & $1.177(1.117-1.240)$ & $<0.001$ & 0.086 & $1.090(1.035-1.148)$ & 0.001 \\
\hline Male (vs female) & 0.298 & $1.347(0.520-3.489)$ & 0.540 & -0.104 & $0.901(0.351-2.310)$ & 0.901 \\
\hline \multicolumn{7}{|l|}{ Marital status (vs with partner) } \\
\hline Without partner & 0.131 & $1.140(0.539-2.412)$ & 0.731 & 0.055 & $1.057(0.488-2.290)$ & 0.888 \\
\hline \multicolumn{7}{|l|}{ Anthropometric measures } \\
\hline Weight & -0.012 & $0.988(0.947-1.030)$ & 0.571 & 0.002 & $1.002(0.960-1.047)$ & 0.910 \\
\hline WHtR $\geq 0.50$ (vs <0.50) & 1.012 & $2.752(1.490-7.452)$ & 0.045 & -0.911 & $0.402(0.063-2.563)$ & 0.402 \\
\hline AC inadequate (vs adequate) & -0.185 & $0.831(0.254-2.715)$ & 0.759 & 0.427 & $1.532(0.424-5.541)$ & 0.515 \\
\hline \multicolumn{7}{|l|}{$\begin{array}{l}\text { BMI (vs } 22.1 \text { - } 26.9 \text { - Healthy } \\
\text { weight) }\end{array}$} \\
\hline BMI $\leq 22-$ low weight & 0.667 & $1.948(0.700-5.419)$ & 0.201 & -0.023 & $0.977(0.345-2.764)$ & 0.965 \\
\hline $\mathrm{BMI} \geq 27$ - overweight & 1.158 & $3.184(1.860-11.794)$ & 0.033 & -0.288 & $0.750(0.158-3.555)$ & 0.717 \\
\hline
\end{tabular}

Note: $\mathrm{WHtR}=$ Waist $/$ height ratio; $\mathrm{BMI}=$ Body Mass Index; OR = Odds Ratio; IC = Interval Confidence; $\mathrm{p} \leq 0.0$

overweight; we used the chi-square test.

To compare the means among gender with age, weight, height, AC for men and women, WHtR, BMI and frailty, we used the Student $t$ test prior to the normal test.

For the multinomial logistic regression analysis, we used as outcomes the EFS categories of "vulnerable" and "frail" with reference to "not frail" category. Demographic variables included in the analysis were age (in years), gender and marital status. Anthropometric measurements analyzed were weight (in kilograms), WHtR, AC and BMI with a 95\% Confidence Interval (CI). For all analyses, results were considered significant when $\mathrm{p} \leq 0.05$.

\section{Results}

There was a predominance of females and subjects with a partner; the mean age was $72.98(\mathrm{SD}=8.16)$ years, weight $68.56(\mathrm{SD}=14.41), \mathrm{AC} 97.47(\mathrm{SD}=13.05)$, BMI (26.94 $(\mathrm{SD}=5.00)$, WHtR $0.60(\mathrm{SD}=0.08)$ and frailty 5.77 $(\mathrm{SD}=3.04)$. There was statistical significance between sex and weight, AC and WHtR (Table 1).

We identified that $89(37.9 \%)$ of the 235 subjects were found to be frail, $57(24.2 \%)$ vulnerable and $89(37.9 \%)$ not frail.

According to analysis, the mean weight for subjects found not frail was $70.57(\mathrm{SD}=14.50)$, vulnerable 70.23 $(\mathrm{SD}=12.82)$ and frail $65.48(\mathrm{SD}=14.90)$ with $\mathrm{p}=0.03 . \mathrm{It}$ was found that the mean AC for not frail was 97.94 (SD $=12.81)$, vulnerable $97.42(\mathrm{SD}=12.64)$ and frail 97.04 (SD = 13.66). For WHtR it was estimated that the mean for the not frail was $0.60(\mathrm{SD}=0.09)$, vulnerable $0.60(\mathrm{SD}=$
0.07), frail 0.61 (SD-0.08). The mean BMI for the not frail is $27.27(\mathrm{SD}=4.67)$, vulnerable $27.00(\mathrm{SD}=4.70)$ and frail $26.57(S D=5.50)$. For the three measurements, we did not observe any statistically significant difference.

It was found that age was related to the EFS categories ( $p<0.001)$ and it increases with age being more evident in the vulnerable and frail categories. However, the most prevalent BMI was in the categories of $\leq 22$ and $\geq 27 \mathrm{~kg}$ / $\mathrm{m} 2$ and association between the frail elderly $(\mathrm{p}=0.045)$ (Table 2)

Using the model of multinomial logistic regression, we identified a strong association between age and the likelihood of the subject being frail and/or vulnerable: the greater the age, the greater the risk of being frail (OR $1.177,95 \%$ CI 1.117 - 1.240, p <0.001) and vulnerable (OR $1.090,95 \%$ CI 1.035 to $1.148 ; \mathrm{p}=0.001)$.

It was found that subjects with a WHtR $\geq 0.50$ had $2.752(95 \%$ CI 1.490 to $7.452 ; \mathrm{p}=0.045)$ greater risk of being frail when compared to subjects with a WHtR $<0.50$. In addition, those with a BMI $\geq 27$ had $3.184(95 \%$ CI 1.860 to $11.794, p=0.033)$ greater risk of being frail compared to those with a BMI between 22.1 and $26.9 \mathrm{~kg} /$ m2. (Table 3).

\section{Discussion}

The study shows that a third of the elderly participants were considered frail and there was an association between age and the categories of EFS called vulnerable and frail. In addition, there was an association between WHtR $\geq 0.50$ and $B M I \geq 27 \mathrm{~km} / \mathrm{m} 2$ with the frailty category. 
The EFS evaluation found that a portion of participants were considered frail, consisting predominantly of female participants. A study conducted in Australia with 82 elderly participants found that $48.9 \%$ were considered frail (13). In Ecuador, a study conducted on 311 elderly participants living in the community showed that $31.2 \%$ were frail (14), in Brazil a study of 128 elderly participants evaluated in a unit of the Family Health Strategy found that $30.1 \%$ were frail (15) and in all the studies presented, frailty was measured by the EFS and a predominance in females was observed.

The predominance of frailty in females occurs because of the longer life expectancy of this population (16) the aging process causes reduced muscle mass due to decreased hormone levels (17) - as well as the longlasting implications of life-long situations, such as the performance of domestic activities and restricted economic and social independence $(6,15)$, which have an impact on quality of life.

It was found that the oldest band ( $>80$ years) were considered frail, a trend that was also observed in different national and international studies $(6,15,18)$. A systematic review has shown that with increasing age there is a greater proportion of the number of older people with pre-frail and frail conditions, the authors suggesting that this is a progressive condition at this stage of life becoming significant after 80 years of age (19). This condition may be related to cumulative oxidative cellular stress and modulated by endogenous and exogenous agents leading to damaged deoxyribonucleic acid (DNA) during the aging process (20).

Among the sociodemographic variables of the study, there was a higher proportion of frail participants without a partner, a trend supported by different authors (18). This may be due to the lack of a companion with whom to share day-to-day life, making the most vulnerable more likely to develop this syndrome.

Regarding the anthropometric measurements, it was observed that the mean BMI was lower in those considered frail; similar results were found in a study of 3,075 elderly Brazilians, for which the mean BMI of frail participants was $26.80 \mathrm{~kg} / \mathrm{m} 2$ (6). On the other hand, a study showed that elderly patients with a BMI of $>30$ $\mathrm{kg} / \mathrm{m} 2$ are more likely to be frail compared to not frail participants (21).

During the aging process, physiological changes occur that contribute to an increase in body weight, in females due to the onset of menopause and in males due to a lack of physical activity leading to inactivity (22). Beyond these factors, changes may be related to the activation of inflammatory processes triggering systemic changes, which influence the onset of frailty syndrome in the elderly (17).

The mean AC was similar for those considered frail, vulnerable and not frail. Different data were identified in the Brazilian study of 77 elderly wherein the frail showed greater AC compared to pre-frail and not frail (23).

Abdominal fat accumulation is associated with increased risk of cardiovascular disease (24) as well as the inflammatory process that releases proinflammatory oxytocin with less insulin resistance, which is linked to frailty syndrome, which reduces muscle fiber and muscular strength (6).

The mean WHtR was slightly higher in frail individuals, but it was found that individuals considered not frail had a WHtR higher than 0.50. A study of 867 elderly people found that $81.4 \%$ had inadequate WHtR, and an association with diseases such as diabetes mellitus and hypertension (24).

As regards BMI, a lower mean and higher predominance of frail elderly was observed. Similar results were found in a Brazilian study in which researchers found a lower mean $(26.80 \mathrm{~km} / \mathrm{m} 2)$ and a higher percentage $(24.91 \%)$ in elderly participants categorized as frail compared to not frail (6).

In an Iranian study of participants between 15 and 74 years, the authors found that WHtR was higher than 0.50 in both genders, especially in people aged over 50 years, 0.56 for males and 0.60 for females. In addition, the WHtR score increased according to the different categories of BMI, and was higher among those categorized as overweight and obese (25).

WHtR is a parameter that serves as cardiovascular and metabolic risk indicator, which can be used in different age groups, whilst BMI has the capability of identifying the association of metabolic risk with regard to designing effective strategies for the prevention and treatment of weight gain and obesity (12).

We point out as a limitation of the study that, due to its cross-sectional design, it is not possible to identify a causal relationship between the frailty variable and the demographic variables and anthropometric measures. On the other hand, the cut-off point used in the analysis of WHtR is not specific to the elderly and relates to the general population.

\section{Conclusion}

From the results and associations observed in the study, one can point out that frailty is a feature of old age and that it is dependent on internal factors and lifestyle that can have an impact on quality of life.

This association is reinforced in the data of this study, in which age was associated with the EFS category of vulnerable and frail. In addition, it was observed that a WHtR $\geq 0.50$ and a BMI $\geq 27 \mathrm{~km} / \mathrm{m} 2$ was associated with the frailty category.

Other studies on the elderly have suggested adjusting the WHtR cut-off point as an indicator to help health professionals prevent cardio-metabolic diseases in this age group.

Funding: This work was supported by the Coordination for the Improvement of Higher Education Personnel (CAPES).

Conflict of interest: No potential conflicts of interest exist for any of the authors. 


\section{References}

1. Brazilian Institute of Geography and Statistics. Projection of Brazil and federative units' population. 2013. http://www.ibge.gov.br/apps/ populacao/projecao/. Accesed 24 May 2016.

2. Morley JE., Vellas B, van Kan GA et al. Frailty consensus: A call to action. J Am Med Dir Assoc, 2013;14(6): 392-7.

3. Rockwood K, Mitnitski A. Frailty in relation to the accumulation of deficits. The J Gerontol A, Biol Sci Med Sci, 2007;62(7): 722-727.

4. Collard RM, Boter H, Schoevers RA, Voshaar RCO. Prevalence of frailty in community-dwelling older persons: A systematic review. JAGS, 2012;60(8):1487-92.

5. Bowen ME. The relationship between body weight, frailty, and the disablement process. J Gerontol B Psychol Sci Soc Sci, 2012;67(5):618-26.

6. Moretto MC, Alves RMAA, Neri AL, Guariento ME. Relationship between nutritional status and frailty in Brazilian elderly. Rev Soc Bra Clín Méd, 2012;10(4):267-71.

7. World Health Organization. Obesity. 2012. http://www.who.int/topics/ obesity/en/. Acessed 15 April 2016.

8. Rolfson DB, Majumdar SR, Tsuyuki RT, Tahir A, Rockwood K. Validity and reliability of the Edmonton Frail Scale. Age Ageing, 2006;35(5):526-9.

9. Fabrício-Wehbe SCC, Cruz IR, Haas VJ, Diniz MA, Dantas RAS, Rodrigues RAP. Reproducibility of the Brazilian version of the Edmonton Frail Scale for elderly living in the community. Rev Lat Am-Enfermagem, 2013;21(6):1330-6.

10. Fabrício-Wehbe SCC, Schiaveto FV, Vendrusculo TRP, Haas VJ, Dantas RAS, Rodrigues, RAP. Cross-cultural adaptation and validity of the "Edmonton Frail Scale-EFS" in a Brazilian elderly sample. Rev Lat Am-Enfermagem, 2009;17(6):1043-9.

11. Ministry of Health of Brazil. Primary care notebooks n 38. Strategies for the person's care with chronic disease: obesity. 2014. 1st edition. Brasilia.

12. Ashwell M, Gunn P, Gibson S. Waist-to-height ratio is a better screening tool than waist circumference and BMI for adult cardiometabolic risk factors: Systematic review and meta-analysis. Obes Rev, 2012;13(3):275-86.

13. Nguyen TN, Pepperell D, Morel-Kopp MC, Cumming RG, Ward C, Hilmer $\mathrm{SN}$. Effect of frailty and age on platelet aggregation and response to aspirin in older patients with atrial fibrillation: A pilot study. Cardiol Ther, 2016;5(1):5162.
14. Del Brutto $\mathrm{OH}$, Mera RM, Sedler MJ et al. The effect of age in the association between frailty and poor sleep quality: A population-based study in community-dwellers (The Atahualpa project). J Am Mes Dir Assoc 2016;17(3):269-71.

15. Fernandes HCL, Gaspar JC, Yamashita CH, Amendola F, Alvarenga MRM, Oliveira MAC. Frailty assessment in the elderly assisted at a family health unit. Texto contexto - enferm, 2013;22(2):423-32.

16. Mitnitski A, Collerton J, Martin-Ruiz C et al. Age-related frailty and its association with biological markers of ageing. BMC Med, 2015;13:161

17. Espinoza SE, Fried LP. Risk factors for frailty in the older adult. Clin Geriatr, 2007;15(6):37-44.

18. Woo J, Yu R, Wong M, Yeung F, Wong M, Lum C. Frailty screening in the community using the FRAIL scale. J Am Med Dir Assoc 2015;16(5):412-9.

19. Mello ADC, Engstrom EM, Alves LC. Health-related and socio-demographic factors associated with frailty in the elderly: a systematic review. Cad Saúde Pública, 2014;30(6):1143-68.

20. Mulero J, Zafrilla P, Martinez-Cacha A. Oxidative stress, frailty and cognitive decline. J Nutr Health Aging, 2011;15(9):756-60.

21. García-Esquinas E, García-García FJ, León-Muñoz LM et al. (2015). Obesity fat distribution, and risk of frailty in two population-based cohorts of older adults in Spain. Obesity, 2015;23(4):847-55.

22. Buzzachera CF, Krause MP, Elsangedy $\mathrm{HM}$ et al. Prevalence of overweight, general and central obesity in elderly from Curitiba, Paraná, Brazil. Rev Nutr 2008;21(5):525-533.

23. Bastos-Barbosa RG, Ferriolli E, Coelho EB, Moriguti JC, Nobre F, Lima NK. Association of frailty syndrome in the elderly with higher blood pressure and other cardiovascular risk factors. Am J Hypertens, 2012;25(11):1156-61.

24. Benedetti TRB, Meurer ST, Morini S. Anthropometric indices related to cardiovascular and metabolic diseases in older adults. Rev educ fís UEM 2012;23(1):123-30

25. Gharakhanlou R, Farzad B, Agha-Alinejad H, Steffen LM, Bayati M. Anthropometric measures as predictors of cardiovascular disease risk factors in the urban population of Iran. Arq Bras Cardiol, 2012;98(2):126-35. 